\title{
THE EFFECT OF PRETREATMENT ON MAGNETIC SEPARATION OF FERRUGINOUS MINERALS IN BAUXITE
}

\author{
R. BHIMA RAO, L. BESRA, B.R. REDDY AND G.N. BANERJEE \\ Regional Research Laboratory, Council of Scientific and Industrial Research \\ Bhubaneswar 751 013, India
}

(Received May 31, 1996, accepted July 8, 1996)

\begin{abstract}
Bauxite sample of Jamnagar, India, is suitable for refractory applications after separation of iron minerals. Different magnetic separators and intensities are studied on different treated samples. The results of these investigations indicate that removal of ferruginous minerals from crude sample requires a magnetic intensity of 14000 Gauss. The calcined sample at $800^{\circ} \mathrm{C}$ requires magnetic intensity of about 7000 Gauss, whereas the reduced bauxite needs less than 2000 Gauss for separation of iron and the product achieved contains $76 \% \mathrm{Al}_{2} \mathrm{O}_{3}$ with $62 \%$ iron removal and $69 \%$ $\mathrm{Al}_{2} \mathrm{O}_{3}$ recovery. All these products are suitable for refractory applications.
\end{abstract}

\section{INTRODUCTION}

High-alumina bauxite is used extensively in the manufacture of refractories and abrasives. However, major impurities such as iron, titania, silicon oxides and calcium carbonates that are often present at different levels in the bauxite deposits seriously offset the performance of these refractories. In order to meet the desired technical specifications, these impurities need to be removed by different beneficiation methods.

Magnetic separation has been widely used until recently to remove iron oxides and other weakly magnetic minerals. This often requires preliminary treatment [1] in 
order to enhance the grain boundary detachment between the gangue minerals and valuable minerals [2], to improve magnetic susceptibility [3] and the efficiency of magnetic separation [4]. Most of the attempts to remove iron content from crude bauxite by using high-intensity magnetic separators have met with marginal success [5].

Pre-treatment operations such as scalping the fines, calcination [5] or magnetising roasting $[6,7]$ have thus been frequently used to prepare an ore for magnetic separation. Since such established technologies have not been applied to Indian refractory bauxite, an attempt has been made in this paper to investigate the effect of different pre-treatment methods on selective liberation, efficiency of magnetic separation and enhancement of magnetism.

\section{MATERIALS AND METHODS}

The bauxite sample of Jamnagar mines, Gujarat, India, containing $53 \% \mathrm{Al}_{2} \mathrm{O}_{3}$, with $4.5 \% \mathrm{Fe}_{2} \mathrm{O}_{3}$ (Table 1 ) was stage-crushed. The $\mathrm{d}_{80}$ passing $1 \mathrm{~mm}$ size was scrubbed and scalped. The scalped feed was classified to different sizes. The size fraction below $50 \mu \mathrm{m}$ and the slimes of the scalped feed were reported as $-50 \mu \mathrm{m}$ fraction.

Table 1: Chemical analysis of bauxite

\begin{tabular}{||l|c||}
\hline \multicolumn{1}{|c|}{ Compound } & Percent \\
\hline $\mathrm{Al}_{2} \mathrm{O}_{3}$ & 53.00 \\
\hline $\mathrm{Fe}_{2} \mathrm{O}_{3}$ & 4.50 \\
\hline $\mathrm{CaO}$ & 2.70 \\
\hline $\mathrm{SiO}_{2}$ & 1.70 \\
\hline $\mathrm{TiO}_{2}$ & 2.40 \\
\hline $\mathrm{LOI}$ & 30.60 \\
\hline
\end{tabular}


Close size fractions were subjected to permaroll magnetic separation. Thermal pre-treatment methods were carried out in a standard calcination/roasting furnace. Calcination was carried out at different temperatures varying between 800 and $1000^{\circ} \mathrm{C}$. The calcination time of 30 minutes was constant for all experiments. The feed used for calcination was $-1.0+0.05 \mathrm{~mm}$.

The effect of the calcination temperature on magnetic separation was investigated using the permaroll magnetic separator. The bauxite calcined at $800^{\circ} \mathrm{C}$ was subjected to different magnetic intensities by using laboratory Boxmag-Rapid belt magnetic separator.

The $d_{80}$ passing $8 \mathrm{~mm}$ size bauxite was reduced at $800^{\circ} \mathrm{C}$ with $5 \%$ coke for 30 minutes. This sample was crushed to below $1 \mathrm{~mm}$ size and subjected to the belt magnetic separator at different magnetic intensities. Wet chemical analysis was carried out for determination of alumina and iron.

\section{RESULTS AND DISCUSSION}

Data presented in Table 2 indicate that iron and alumina are equally distributed in all size fractions except in the fines. These observations indicate that by scalping the feed, the fines of $0.05 \mathrm{~mm}$ size can be removed ranging between 18 and $20 \%$ by mass containing $4.5 \%$ Fe.

Table 2: Size and chemical analysis of crushed product

\begin{tabular}{||c|c|c|c||}
\hline Size, $\mathrm{mm}$ & $\mathrm{Wt} \%$ & $\mathrm{Fe} \%$ & $\mathrm{Al} \%$ \\
\hline 1.00 & 32.40 & 3.70 & 28.50 \\
\hline 0.50 & 8.80 & 3.10 & 27.40 \\
\hline 0.25 & 16.30 & 3.20 & 27.50 \\
\hline 0.12 & 13.10 & 3.50 & 28.40 \\
\hline 0.05 & 10.60 & 2.80 & 28.00 \\
\hline-0.05 & 18.80 & 4.50 & 27.90 \\
\hline Total & 100.00 & 3.60 & 28.10 \\
\hline
\end{tabular}


The effect of magnetic separation on close sized fractions is shown in Table 3. The data indicate that separation of iron can be possible in the size ranges between 0.5 and $0.05 \mathrm{~mm}$. Thus, by classifying the feed at $1 \mathrm{~mm}$ and $0.05 \mathrm{~mm}$, a non-magnetic product containing $35 \%$ by mass and $2.4 \% \mathrm{Fe}$ could be achievable.

Table 3: Magnetic separation of a crushed product using permarolls

\begin{tabular}{|c|c|c|c|c||}
\hline \multirow{2}{*}{ Size, $\mathrm{mm}$} & \multicolumn{2}{|c|}{ Magnetics } & \multicolumn{2}{c|}{ Non-magnetics } \\
\cline { 2 - 5 } & $\mathrm{Wt} \%$ & $\mathrm{Fe} \%$ & $\mathrm{Wt} \%$ & $\mathrm{Fe} \%$ \\
\hline 1.00 & 1.30 & 15.50 & 31.10 & 3.20 \\
\hline 0.50 & 1.00 & 13.50 & 7.80 & 1.70 \\
\hline 0.25 & 3.10 & 9.40 & 13.20 & 1.70 \\
\hline 0.12 & 3.70 & 8.20 & 9.40 & 1.60 \\
\hline 0.05 & 5.60 & 4.80 & 5.00 & 0.60 \\
\hline-0.05 & 3.50 & 10.70 & 15.30 & 3.10 \\
\hline Total & 18.20 & 9.20 & 81.80 & 2.50 \\
\hline \hline
\end{tabular}

The effect of heat treatment on removal of iron by using permaroll magnetic separation is shown in Table 4. As expected, with increasing temperature from oven to furnace temperature, the iron content in the feed increases. It is also seen that with increasing temperature the percentage of iron removal is progressive.

Table 4: Effect of heat treatment on permaroll magnetic separation

\begin{tabular}{|c|c|c|c|c|c|c||}
\hline \multirow{2}{*}{ Temp. ${ }^{\circ} \mathrm{C}$} & \multicolumn{2}{|c|}{ Magnetics } & \multicolumn{2}{c|}{ Non-magnetic } & \multirow{2}{*}{$\begin{array}{c}\text { Feed } \\
\text { Fe\% }\end{array}$} & $\begin{array}{c}\text { Removal } \\
\mathrm{Fe} \%\end{array}$ \\
\cline { 2 - 5 } & $\mathrm{Wt} \%$ & $\mathrm{Fe} \%$ & $\mathrm{Wt} \%$ & $\mathrm{Fe} \%$ & & 68.60 \\
\hline 100.00 & 33.60 & 7.40 & 66.40 & 1.70 & 3.60 & 68.0 \\
\hline 800.00 & 44.80 & 6.80 & 55.20 & 1.70 & 4.00 & 76.20 \\
\hline 900.00 & 49.00 & 6.80 & 51.00 & 1.70 & 4.20 & 79.30 \\
\hline $1,000.00$ & 50.70 & 7.50 & 49.30 & 1.80 & 4.70 & 80.90 \\
\hline
\end{tabular}


These findings are observed due to a loss of moisture in the sample. It is also expected that with increasing temperature at certain atmosphere the feebly magnetic iron minerals may be attracted by higher magnetic field resulting in the increased mass percentage of magnetics.

Thus the results of these observations indicate that the oven dried sample may require 14000 Gauss for separation of iron, whereas the calcined sample seems to require lower magnetic field for separation of partially converted magnetic minerals.

The results of different magnetic fields on calcined $\left(800^{\circ} \mathrm{C}\right)$ sample are shown in Table 5. These results indicate that at the magnetic intensity of 1000 Gauss, about 28 to $30 \%$ magnetics containing $14.8 \% \mathrm{Fe}$ could be rejected. Due to the scalping of highly magnetic particles by stages raise magnetism, a non-magnetic product containing $56 \%$ by mass with $1.7 \%$ Fe could be achievable compared to a product obtained from uncalcined feed at 14000 Gauss by permaroll magnetic separation.

Table 5: Effect of magnetic intensity on calcination of crude bauxite

\begin{tabular}{||c|c|c|c||}
\hline Magnetic intensity, G & Product & Weight \% & $\mathrm{Fe} \%$ \\
\hline $1,000.00$ & Mag1 & 28.50 & 14.80 \\
\hline $1,300.00$ & Mag2 & 2.00 & 2.40 \\
\hline $1,800.00$ & Mag3 & 2.20 & 2.00 \\
\hline $2,500.00$ & Mag4 & 2.10 & 2.00 \\
\hline $3,400.00$ & Mag5 & 2.80 & 1.90 \\
\hline $4,500.00$ & Mag6 & 3.20 & 1.90 \\
\hline $7,100.00$ & Mag7 & 4.00 & 1.80 \\
\hline $7,100.00$ & Non-mags & 56.20 & 1.70 \\
\hline \multicolumn{2}{|c|}{ Total } & 100.00 & 5.50 \\
\hline \hline
\end{tabular}

Since it is observed that heat treatment has an advantage of enhancing the magnetism of the particles as well as improves the separation efficiency, the crude 
sample was roasted under reducing atmosphere and subjected to magnetic separation after size reduction. The results of the effect of magnetic intensity on reduced sample shown in Table 6 indicate that a non-magnetic product containing $1.8 \% \mathrm{Fe}$ with $63 \%$ yield could be achievable at 1800 Gauss compared to a calcined sample at 7100 Gauss and oven-dried sample at 14000 Gauss.

Table 6: Effect of magnetic intensity on roasting of crude bauxite

\begin{tabular}{||c|c|c|c||}
\hline Magnetic intensity, G & Pivuluci & Weight, \% & Fe, \% \\
\hline $1,000.00$ & Mag1 & 14.60 & 19.00 \\
\hline $1,300.00$ & Mag2 & 10.60 & 12.50 \\
\hline $1,800.00$ & Mag3 & 11.20 & 2.00 \\
\hline $1,800.00$ & Non-mags & 63.30 & 1.80 \\
\hline \multicolumn{2}{|c|}{ Total } & 100.00 & 5.50 \\
\hline
\end{tabular}

Summary of the results shown in Table 7 indicate that at 1400 Gauss a non-magnetic product containing $53 \% \mathrm{Al}_{2} \mathrm{O}_{3}$ and $2.2 \% \mathrm{Fe}_{2} \mathrm{O}_{3}$ could be obtained with $86 \%$ iron removal and $36 \%$ alumina recovery from an oven-dried sample. At 7000 Gauss the calcined sample gave a product containing $76 \% \mathrm{Al}_{2} \mathrm{O}_{3}$ with $77 \%$ iron removal and $56 \% \mathrm{Al}_{2} \mathrm{O}_{3}$ recovery. Reduced sample, at below 2000 Gauss, also gave a product containing $77 \% \quad \mathrm{Al}_{2} \mathrm{O}_{3}$ with $62 \%$ iron removal and $69 \% \mathrm{Al}_{2} \mathrm{O}_{3}$ recovery. All the end products obtained at 14000 Gauss, 7100 Gauss and 1800 Gauss are suitable as a raw material for refractory applications.

\section{CONCLUSIONS}

The iron content is distributed equally at all size fractions in the bauxite sample. Removal of ferruginous minerals from crude sample requires 14000 Gauss for obtaining a product containing $53 \% \mathrm{Al}_{2} \mathrm{O}_{3}$ with $36 \%$ recovery. The calcined sample at $800^{\circ} \mathrm{C}$ requires magnetic intensity of about 7000 Gauss for obtaining $76 \% \mathrm{Al}_{2} \mathrm{O}_{3}$ with $56 \%$ recovery, whereas the reduced bauxite needs less than 2000 Gauss for 
Table 7: Summary of results and chemical analysis of the non-magnetic products

\begin{tabular}{||l|c|c|c||}
\hline \multicolumn{1}{|c|}{ Parameter } & Oven-dried & Calcined & Roasting \\
\hline Magnetic field, $\mathrm{G}$ & $14,000.00$ & $7,100.00$ & $1,800.00$ \\
\hline Yield (\%) & 35.40 & 56.20 & 63.30 \\
\hline Recovery $\left(\% \mathrm{Al}_{2} \mathrm{O}_{3}\right)$ & 36.00 & 56.00 & 69.00 \\
\hline${\operatorname{Removal}\left(\% \mathrm{Fe}_{2} \mathrm{O}_{3}\right)}^{8}$ & 86.00 & 77.00 & 62.00 \\
\hline $\mathrm{Al}_{2} \mathrm{O}_{3}(\%)$ & 53.80 & 75.80 & 77.00 \\
\hline $\mathrm{Fe}_{2} \mathrm{O}_{3}(\%)$ & 2.20 & 2.40 & 2.50 \\
\hline $\mathrm{CaO}^{(\%)}$ & 1.70 & 2.40 & 2.50 \\
\hline $\mathrm{SiO}_{2}(\%)$ & 1.70 & 2.40 & 2.50 \\
\hline $\mathrm{TiO}_{2}(\%)$ & 2.40 & 3.80 & 3.80 \\
\hline \hline
\end{tabular}

separation of iron and the product achievable contain $77 \% \mathrm{Al}_{2} \mathrm{O}_{3}$ with $69 \%$ recovery. All these products are suitable for refractory applications.

\section{ACKNOWLEDGEMENTS}

The authors are grateful to Prof. H.S. Ray, director of this laboratory for his encouragement and permission to publish this paper. Thanks are also due to the technical staff for their help during experiments and analysis.

\section{REFERENCES}

[1] J. Svoboda: Magnetic Methods for the Treatment of Minerals. Elsevier, New York 1987, p. 451-565

[2] R. Bhima Rao, B. Das, M.I. Ansari and V. Mahadevan: Pretreatment of lead zinc ore by microwaves: an improved method to recover metal values. Intl. Series on Chemical Engineering. Utilisation of natural resources 
chemical engineering approach. H.S. Ray and A.K. Mitra (Eds.), Publications \& Information Directorate and Wiley Eastern Ltd., New Delhi, 1994, p. 31-37

[3] R. Bhima Rao: A novel approach in the beneficiation of ferruginous bauxite by microwave treatment. SME Trans. (accepted for publication)

[4] R. Bhima Rao, K.K. Bhattacharya and M.I. Ansari: Beneficiation of ferruginous bauxite ore. IM\&EJ, March 1991, p. 17-19

[5] L.Y. Sadler and C. Venkataraman: A process for enhanced removal of iron from bauxite ores. IJMP 31 (1991), 233-246

[6] H. Rausch and H. Meiler: Magnetising roasting of iron ore. US Patent No. $335345(1967)$

[7] B.R. Reddy, R. Bhima Rao, L.D. Besra, S.K. Misra, D.K. Dey, G.N. Banerjee and H.S. Ray: Upgradation of low grade bauxite for refractory and ceramic applications. Report No. T/PM/118/95 for Department of Sciences and Technology and Regional Research Laboratory, India (1995).

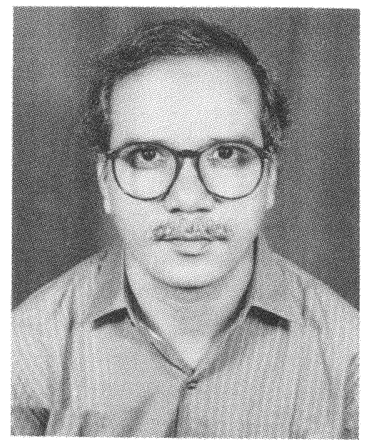

R. Bhima Rao graduated in geology and post-graduated in applied geology and mineral process engineering from Andhra University, Visakhapatnam, India. He obtained his doctorate degree from Indian School of Mines, Dhanbad, India.He was a visiting scientist at the Lulea University of Technology, Sweden. His major field of interest is comminution, gravity concentration and process flowsheet development. Dr. Bhima Rao is an author of publications, reports and patents.

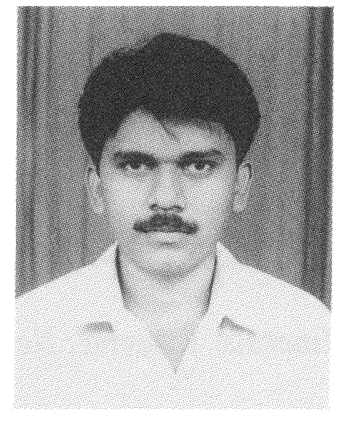

L. Besra obtained his Bachelors degree in metallurgical engineering from Regional Engineering College, Rourkela in 1991, and his Masters degree in metallurgical engineering from Indian Institute of Science, Bangalore in 1993. Presently he is a scientist at the Regional Research Laboratory Bhubaneswar. His research interest are beneficiation of low-grade ores, fine particle processing including dewatering sludges. He is an author of six publications. 


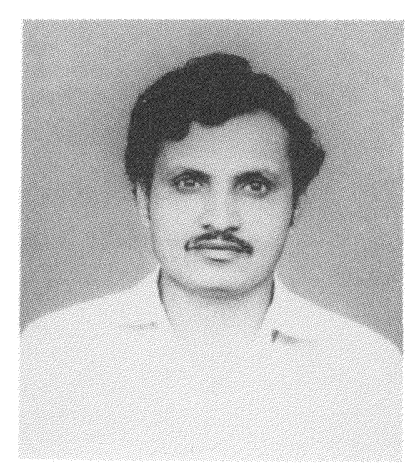

B.R. Reddy obtained his masters degree in chemistry in 1975 and received his Ph.D. for work in solvent extraction from Sri Venkateswara University, Tirupati, India, in 1981. He took up a position of scientist with the Regional Research Laboratory (CSIR), Bhubaneswar, in 1982 and his main interest is extractive metallurgy of non-ferrous metals.

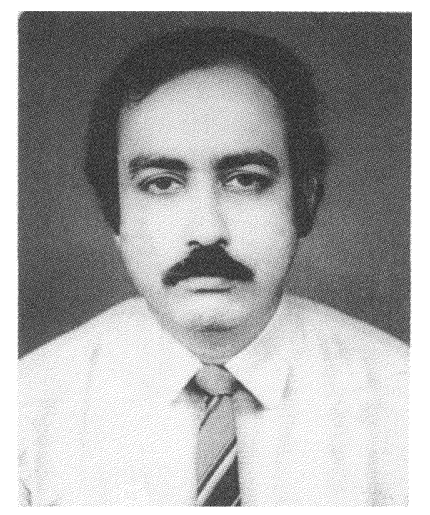

G.N. Banerjee obtained his degrees of B.Tech. and M.Tech. in chemical engineering from the University College of Science and Technology, Calcutta, in 1973 and 1975 , respectively. He joined the Regional Research Laboratory (CSIR), Bhubaneswar in 1980 where he holds a position of scientist. He is currently working in the area of extractive metallurgy, particularly on high-temperature roasting and agglomeration of ores and fines.

Keywords: magnetised roasting, permroll, belt magnetic separator, hematite, magnetite, bauxite 